\title{
Ethanolic extract of sappan wood (Caesalpinia sappan L.) inhibits MCF-7 and MCF-7/HER2 mammospheres' formation: an in vitro and bioinfor- matic study
}

\author{
Dhania Novitasari $^{1}$, Laeli Muntafiah ${ }^{1}$, Nur Fitra Sari ${ }^{1}$, Edy Meiyanto ${ }^{1,2}$, Adam Hermawan $^{1,2, *}$ \\ ${ }^{1}$ Cancer Chemoprevention Research Center (CCRC), Faculty of Pharmacy, Universitas Gadjah Mada, Sekip Utara, Yogyakarta 55281, \\ Indonesia \\ 2Laboratory of Macromolecular Engineering, Department of Pharmaceutical Chemistry, Faculty of Pharmacy, Universitas Gadjah Mada, \\ Sekip Utara, Yogyakarta 55281, Indonesia \\ *Corresponding author: adam_apt@ugm.ac.id
}

SUBMITTED 23 January 2021 REVISED 27 May 2021 ACCEPTED 3 June 2021

\begin{abstract}
One of the mechanisms of cancer cell resistance toward chemotherapy is through cancer stem cells (CSCs), which are characterized by excessive activation of regulator proteins such as human epidermal receptor 2 (HER2). Sappan wood (Caesalpinia sappan L.) contains brazilin and brazilein that exhibit cytotoxic effects on several cancer cell lines. We aimed to explore the potency of the ethanolic extract of sappan (EES) in CSCs through bioinformatic analyses and by using a three-dimensional (3D) breast cancer stem cells (BCSCs) for in vitro assay with two different models (i.e., BCSCs and HER2BCSCs) in order to identify the potential therapeutic targets of genes (PTTGs). Bioinformatic analyses identified PTTGs, which were further analyzed by gene ontology, Kyoto Encyclopedia of Genes and Genomes (KEGG) pathway enrichment, protein-protein interaction (PPI) networks, and hub protein selection. Mammospheres were cultured under conditioned media. The cytotoxic effects of EES were then measured by direct counting and based on the mammosphere-forming potential (MFP). Bioinformatic analysis disclosed PIK3CA and TP53 as PTTGs in BCSCs and HER2-BCSCs, respectively. In addition, the KEGG pathway analyses also demonstrated that PTTGs could regulate the ERBB pathway. EES thus demonstrated cytotoxicity and inhibited the formation of mammospheres. Collectively, EES exhibited excellent potential for further development as an inhibitor of cancer stem cells in breast cancer.
\end{abstract}

KEYWORDS Bioinformatics; breast cancer stem cells; sappan wood (Caesalpinia sappan L.)

\section{Introduction}

Cancer remains one of the diseases with the largest numbers of death associated with it owing to the abnormality of cell proliferation involved in this condition (Garraway and Jänne 2012). Several approaches of establishing chemotherapeutic drugs targeted on several cancer pathways have been developed to treat such patients (Cortés et al. 2014). The breakthrough of cancer treatment has extensively changed over the past two decades, from targeted cell proliferation to the use of specific markers on cancer cells, which are generally less toxic (Kroschinsky et al. 2017). Despite the fact that, relative to the situation several years ago, the development of cellular resistance to a specific treatment has been a significant concern contributing to the failure of therapy in cancer (Garraway and Jänne 2012).

One of the significant failures of cancer therapy is the acquired chemoresistance of cancer cells. The administration of a chemotherapy agent is conducted through re- peated cycles. However, residual cancer cells remain a small subset called as the cancer stem cells (CSCs) that possess self-renewal and differentiation capabilities into heterogeneous tumor cells, which are believed to affect the recurrence of cancer cells (Koury et al. 2017). The hallmarks of CSCs are marked with the cells' capability to inactivate drugs, alter targeted cells, and overexpress regulatory proteins such as the human epidermal receptor 2 (HER2) (Korkaya et al. 2008). The use of mammospheres was the highlight of this study because it resembled the body's actual tumor. It also revealed the differences in the cellular properties when compared to the usual twodimensional (2D) monolayer culture (Oak et al. 2012) and increased the CSCs properties in mammospheres (Wang et al. 2014).

Caesalpinia sappan L. or Sappan-a natural product from Indonesia-has been known to profoundly inhibit tumor growth in numerous cancer cells as well as in breast cancer (Kim et al. 2005; Khamsita et al. 2012; Nurzijah 
et al. 2012; Rachmady et al. 2016; Rivanti et al. 2016; Naik Bukke et al. 2018; Hanif et al. 2019; Meiyanto et al. 2019). Significantly, the anticancer activity from sappan is mediated via several mechanisms: inhibiting the cell cycle progression, triggering apoptosis, decreasing the reactive oxygen species (ROS) level and senescence, inhibiting cancer cells' migration by suppressing the matrix metalloproteinase-9 (MMP-9) activity, and inhibiting the HER2 expression (Khamsita et al. 2012; Haryanti et al. 2016; Rachmady et al. 2016; Hanif et al. 2019). Two major compounds in C. sappan: brazilin and brazilein, also demonstrated remarkable outcomes in inhibiting tumor growth through the respective predictive mechanisms mentioned above (Handayani et al. 2017; Jenie et al. 2018, 2020) and targets in several proteins responsible for cancer metastasis, including MMP-9 via NF-kB, MMP-2, and Rac1 proteins (Kim et al. 2012; Hsieh et al. 2013; Handayani et al. 2016).

This study focused on examining the potency of the ethanolic extract of sappan (EES) in breast cancer stem cells (BCSCs) using 3D mammospheres from MCF-7 and MCF-7/HER2 breast cancer cells. Moreover, integrated bioinformatics was also utilized in predicting the potential therapeutic target of genes (PTTGs) from EES in BCSCs and HER2-BCSCs, thereby highlighting the relationship between EES and inhibition in BCSCs. Our findings from this study can be fundamental for the development of EES as an alternative agent for the inhibition of CSCs on breast cancer cells and overcoming chemotherapy resistance.

\section{Materials and Methods}

\subsection{Protein-protein interaction (PPI) network and hub genes analysis}

We analyzed seven compounds found in sappan wood (i.e., Butein, Sappanchalcone, Protosappanin A, Sappanone B, Euxanthone, Brazilein, and Brazilin) (Cuong et al. 2012; Nirmal et al. 2015) to discover the possible involvement from EES in BCSCs. Direct protein targets (DTPs) of each compound were collected from STITCH (Kuhn et al. 2014). Indirect protein targets (ITPs) were downloaded from STRING-DB v11 with a confidence score of 0.7 and no more than 20 interactions (Szklarczyk et al. 2015). The regulatory genes of BCSCs and HER2-BCSCs regulatory genes were collected from OMIM and PubMed, respectively. All cumulative DTPs and ITPs were then called potential therapeutics target genes (PTTGs). A Venn diagram was prepared between the target genes of EES compounds and BCSCs-regulatory genes and HER2-BCSCs regulatory genes. The gene list was constructed for the protein-protein interaction (PPI) network with STRINGDB v11 (Szklarczyk et al. 2015), with confidence scores $>0.7$ that were considered significant. Further analysis of the PPI network was visualized by the Cytoscape (Shannon et al. 2003).

\subsection{Gene ontology (GO) and Kyoto Encyclopedia of Genes and Genomes (KEGG) pathway analysis}

We utilized the GO and KEGG pathway enrichment analysis were conducted as previously conducted by Hermawan and Putri (2020) by using WebGestalt (WEB-based GEne SeT AnaLysis Toolkit) with the Over-Representation Enrichment Analysis (ORA), $p<0.05$ was used as the threshold value (Wang et al. 2017).

\subsection{Analysis of genetic alterations of the potential therapeutics target genes (PTTGs)}

The genetic alterations of the PTTGs were generated using the cBioPortal (Cerami et al. 2012; Gao et al. 2013). The breast cancer study with the top genetic alterations was selected for subsequent connectivity analysis $(p<0.05$ as the cutoff value).

\subsection{Sample preparation}

The heartwood of sappan powder was obtained from the Balai Besar Penelitian dan Pengembangan Tanaman Obat dan Obat Tradisional (B2P2TOOT), Tawangmangu, Indonesia, and was determined in the Faculty of Pharmacy, Universitas Gadjah Mada. The extraction of heartwood was performed according to Meiyanto et al. (2019). Briefly, $500 \mathrm{~g}$ of the powder was extracted through maceration of $70 \%$ ethanol in 5 days, followed by evaporation using a rotary vacuum evaporator to obtain EES. The extraction process yielded $115 \mathrm{~g}$ of EES (23\%). Later, the extract was authenticated by thin-layer chromatography (TLC) for Brazilein/Brazilin content.

\subsection{Cell culture}

MCF-7 breast cancer cells, both wild-type and transfected with pcDNA5/TO-HER2 gene that overexpressed HER2 (MCF-7/HER2), were kindly provided by the Nara Institute of Science Technology, Japan. The cells were cultured in DMEM high glucose (Gibco, Invitrogen, USA) supplemented with 10\% fetal bovine serum (FBS; Gibco), 1.5\% penicillin-streptomycin (Gibco), and 0.5\% Fungizone (Gibco) at $37{ }^{\circ} \mathrm{C}$ under $5 \% \mathrm{CO}_{2}$ incubator. TrypsinEDTA $0.25 \%$ (Gibco) was used to harvest the cells. The cells were cultured in the PolyHEMA (Sigma, St. Louis, CA, USA) coated tissue culture dish with conditioned media to generate mammosphere. Dimethylsulfoxide (DMSO; Merck, Germany) was added to dilute EES at a $10^{5} \mu \mathrm{g} / \mathrm{mL}$ concentration.

\subsection{Mammosphere generation and cytotoxicity}

Mammosphere generation and cytotoxicity were performed as previously described by Oak et al. (2012) and Grimshaw et al. (2008). Briefly, the MCF-7 and MCF-7/HER2 cells were seeded $\left(4 \times 10^{4}\right.$ cells $\left./ \mathrm{mL}\right)$ in PolyHEMA (50 mg/mL)-coated plate using conditioned medium. The cells were allowed to grow and form mammospheres for 3 days before the cytotoxic test. To perform cytotoxicity, the prepared mammospheres were incubated for the following $48 \mathrm{~h}$ with EES. At the end of the incuba- 
tion period, the mammospheres were observed by an inverted microscope and counted directly.

\subsection{Mammosphere-forming inhibition}

The cells were pre-treated with EES for $24 \mathrm{~h}$ before seeding $\left(10^{4}\right.$ cells/well) in PolyHEMA (Sigma Aldrich, MO, USA) coated 24-well plates and were further incubated for $72 \mathrm{~h}$. At the end of the experiment, the mammosphere was counted manually and presented as mammosphereforming potential (MFP), which was calculated as the number of mammosphere per 10,000 cells $( \pm S E$ ) (Wang et al. 2014).

\subsection{Data analyses}

For the cytotoxic assay, cell viability was calculated and plotted into EES concentration versus cell viability (percent of control) using the GraphPad Prism (GraphPad Software, San Diego, California, USA). Mammosphere (MS) formed (per $1 \times 10^{4}$ cells/well) was manually counted and analyzed as MFP (MS per $1 \times 10^{4}$ cells).

\section{Results and Discussion}

\subsection{The analysis of the PPI network of PTTGs of Cae- salpinia sappan $L$.}

This study investigated the molecular target from the EES in breast cancer using bioinformatics and in vitro approaches. A total of 687 genes was generated from 7 compounds (Supplementary Table 1). We collected 1280 regulatory genes of BCSCs (Supplementary Table 2) and 171 HER2-BCSCs regulatory genes (Supplementary Table 3) from OMIM and PubMed, respectively. We found out 146 and 56 genes were the target genes of EES compounds in BCSCs-regulatory genes and HER2-BCSCs regulatory genes, respectively (Supplementary Tables 4 and 5).

We then established all the genes into the PPI network using STRING and visualized them using the Cytoscape. The top genes related to BCSCs with the highest degree score were recognized as EGFR, EGF, PIK3R1, TP53, PIK3CA, AKT1, STAT3, VEGFA, MAPK1, and IL6 (Figure 1a), whereas KRAS, MYC, and $C D H 1$ were present as a part of PTTGs in HER2-BCSCs (Figure 1b). The difference between these results indicated the HER2-signaling pathway alters the molecular mechanism in BCSCs.

\subsection{GO analysis of PTTGs related to BCSCs and HER2- BCSCs}

GO analysis of PTTGs was classified into three groups: biological process, cellular component, and molecular function (Figure 2). Among the PTTGs in BCSCs and HER2BCSCs participated in the biological processes of response stimulus, biological regulation, and metabolic process. In addition, the PTTGs were located in the membrane, nucleus, and cytosol, which play an essential role in the molecular function in protein, ion, nucleic acid binding, and enzyme regulator activities. KEGG enrichment indicated several pathways regulated by PTTGs (Supple- mentary Tables 6 and 7), such as cancer and the HER2signaling pathways. Several PTTGs were involved in these signaling pathways, including KRAS, JUN, MMP9, EGFR, MAPK1, and PI3KCA.

\subsection{Genetic alterations among the hub proteins of PTTGs}

A total of 11 potential target genes of PTTGs were analyzed using the cBioportal in order to explore their genomic alterations across BCSCs and HER2-BCSCs. AKT1, EGFR, PIK3CA, PIK3R1, MAPK1, KRAS, MYC, and TP53 were selected from the highest degree score using the Cytoscape and KEGG pathway enrichment analysis, while MMP9 was selected from the KEGG pathway analysis. The METABRIC studies (Lefebvre et al. 2016) were selected for subsequent analyses. Genetic alterations for each target gene were revealed in BCSCs with the highest percentage from PIK3CA (42\%), followed by $A K T 1$ (5\%) and EGFR (4\%) (Figure 3a). On the other hand, in HER2-BCSCs, Oncoprint analyses revealed that genetic alterations of PTTGs occurred in 4-42\% of patients' samples, dominated by p53 amplification, which is present as the most common gene alteration (Figure 3b). This finding indicated that the involvement of HER2 may change the genetic alterations in BCSCs.

\subsection{EES inhibits mammosphere formation and growth in BCSCs and HER2-BCSCs}

We successfully generated mammospheres from MCF7/HER2 with a density of 10,000 cells/well, using the same procedure as previously mentioned. Mammospheres were formed from the MCF-7/HER2 cells in 3-7 days (Figure 4a). Next, we treated the mammospheres with EES in order to determine the cytotoxic effect on mammospheres by the MTT assay. The treatment of EES for $48 \mathrm{~h}$ reduced the mammospheres' viability from MCF-7 and MCF-7/HER2 (Figure 4b). Interestingly, the data itself demonstrated that EES appeared more sensitive on the mammospheres from MCF-7 than from MCF-7/HER2, as assessed by the lowest tested concentration $(10 \mu \mathrm{g} / \mathrm{mL})$ caused a decrease of viable cells up to $70 \%$ in BCSC. Simultaneously, it required a higher dose of EES to inhibit the mammosphere growth in HER2-BCSCs. Our data also demonstrated that the treatment using EES significantly $(p<0.001)$ inhibited mammospheres formation based on MFP (Figure 4c). These findings collectively highlighted the potential of EES as a potential candidate for BCSCs and HER2BCSCs-targeted therapy.

\subsection{Discussion}

In this study, we aimed to determine the effect of the EES in BCSCs and HER2-BCSCs through a bioinformatic approach and the in vitro assay. Integrated bioinformatics analysis retrieved through STITCH and STRING resulted from PTTGs of EES in BCSCs. Hub proteins included EGFR, VEGFA, p53, STAT3, and PIK3CA in both BCSCs and HER2-BCSCs. These targets were a part of receptor tyrosine kinase (RTK) pathways associated with in- 

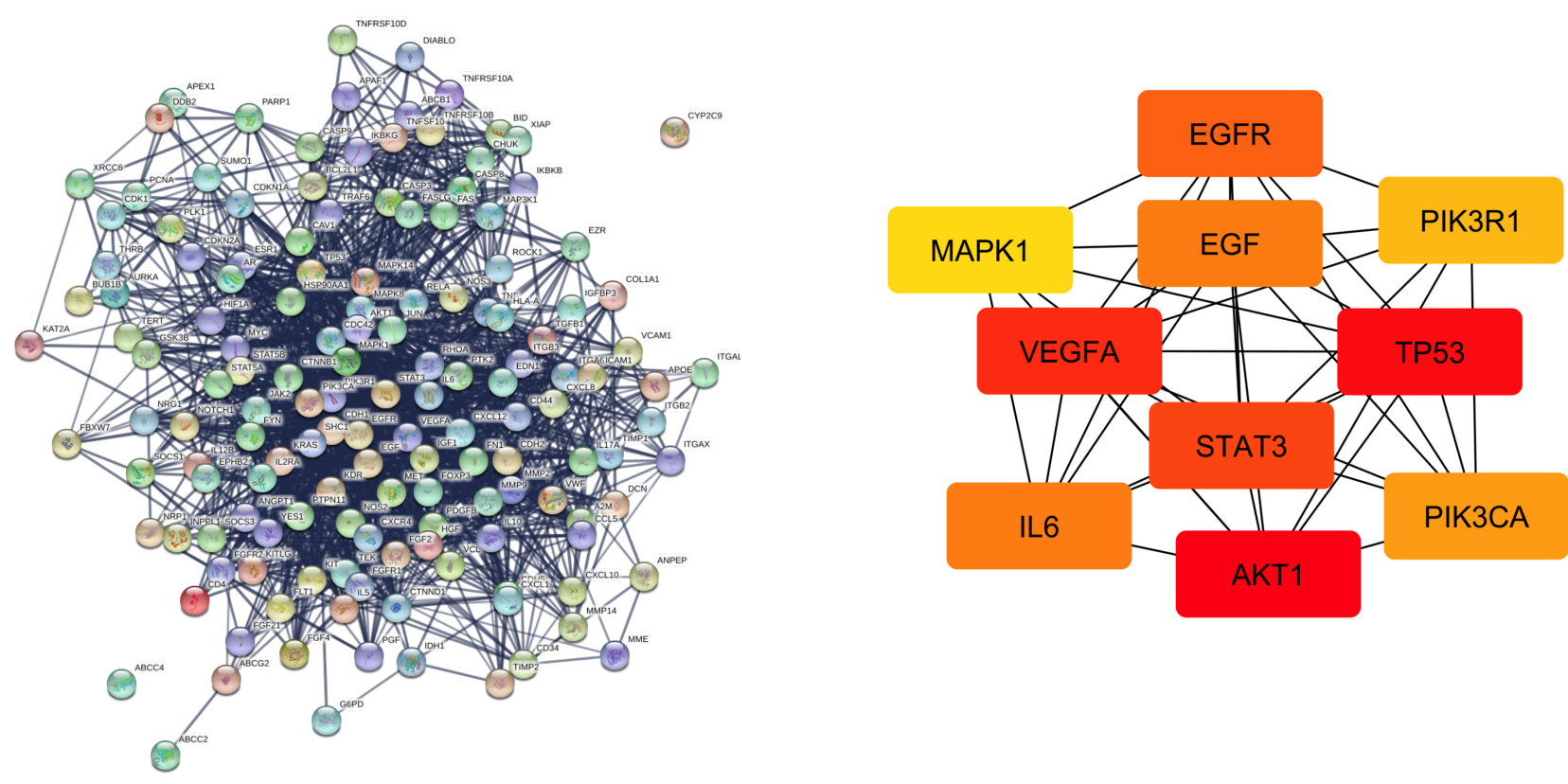

(a)
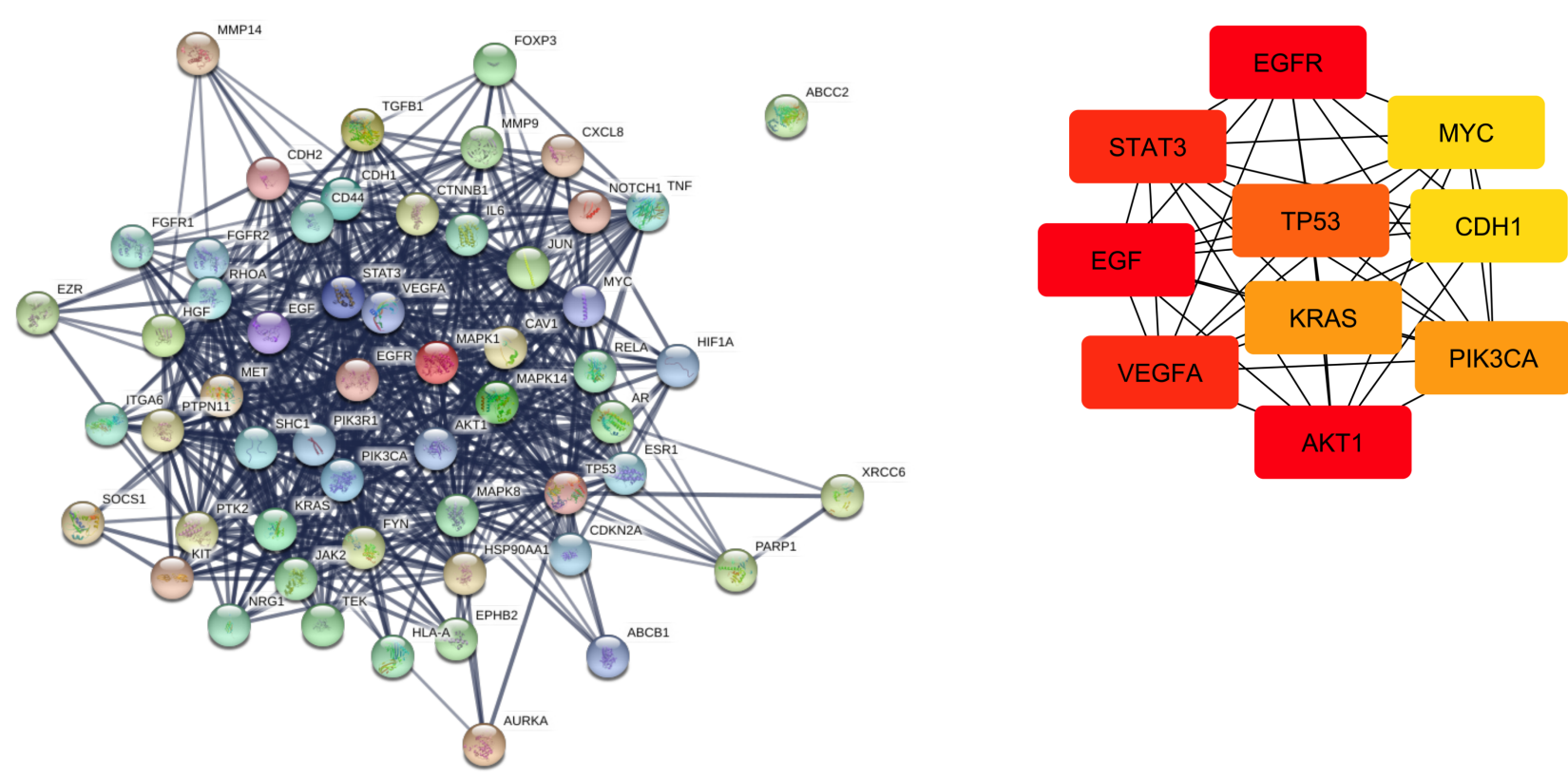

(b)

FIGURE 1 The PPI network of PTTGs (analyzed by STRING) and hub genes (analyzed by CytoScape) of Caesalpinia sappan related to (a) BCSCs and (b) HER2-BCSCs.

creased breast cancer aggressiveness (Butti et al. 2018). It is also knowledgeable that EGFR signaling was also responsible for the significant pathways including Ras-RafMAPK, PI3K/Akt, JNK/STAT, and PLCץ, which affected a plethora of biological functions (Masuda et al. 2012). GO enrichment analysis demonstrated that PTTGs are involved in the biological processes of response to the stimulus (as defined as a change in the state or activity of a cell in terms of movement, secretion, enzyme production, and gene expression). The PTTGs were located in the membrane, cytosol, and nucleus. Furthermore, the PTTGs played a molecular function in protein binding, both in BCSCs and HER2-BCSCs. The KEGG's pathway based on PTTGs revealed the ERBB-signaling pathway regulation that also correlates with a prior analysis with STRING (Figure 1). ERBB signaling plays a critical part in proliferation, differentiation, survival, and migration (Arteaga 2011). Once this pathway was dysregulated, the cell proliferation becomes uncontrollable and promotes cellular malignancies. The two most widely studied proteins in the ERBB family: ERBB1 (HER1 or EGFR) and ERBB2 (HER2), was profoundly known to lead to the progression 
Bar chart of Biological Process categories

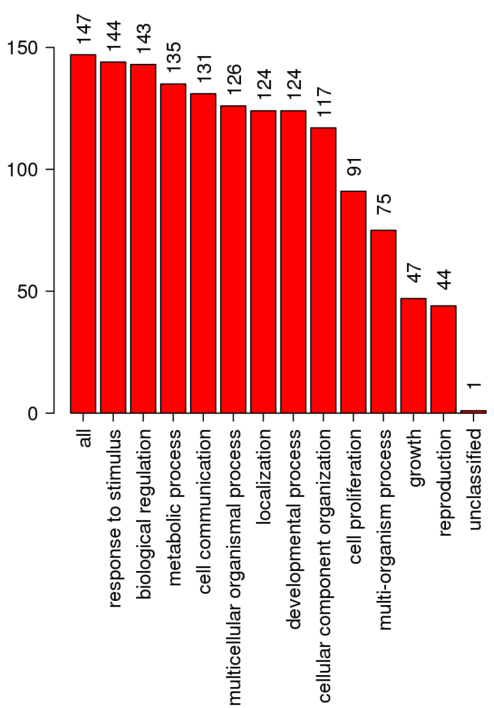

(a)

Bar chart of Biological Process categories

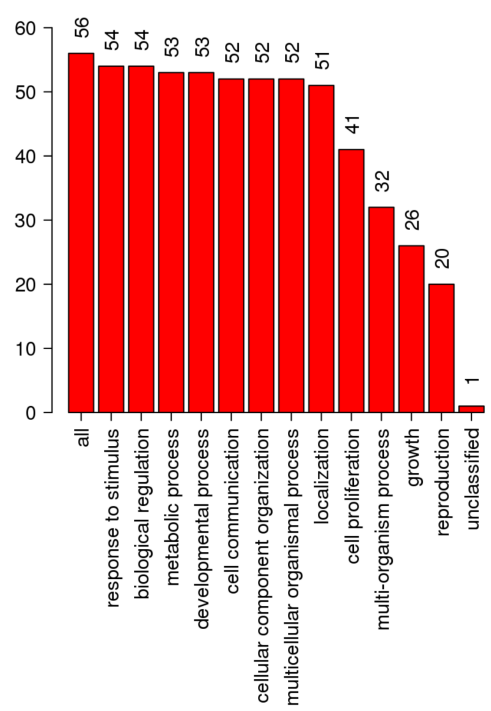

Bar chart of Cellular Component categories

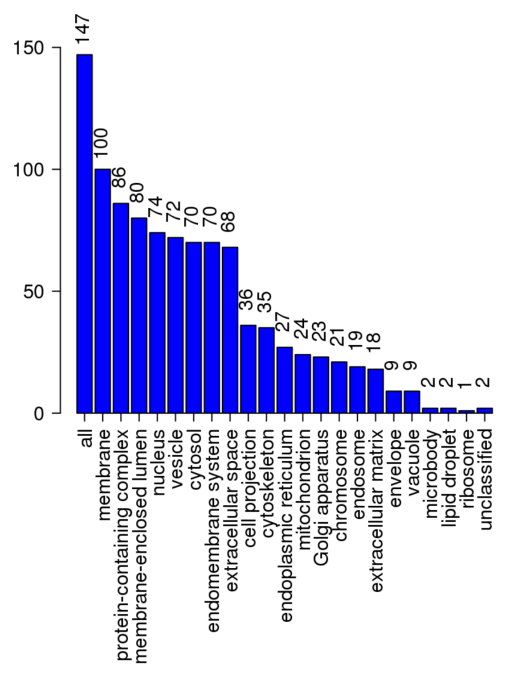

Bar chart of Cellular Component categories

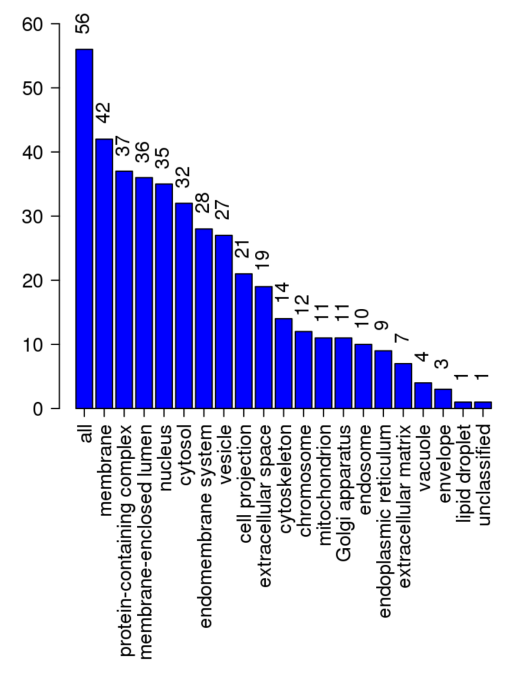

Bar chart of Molecular Function categories

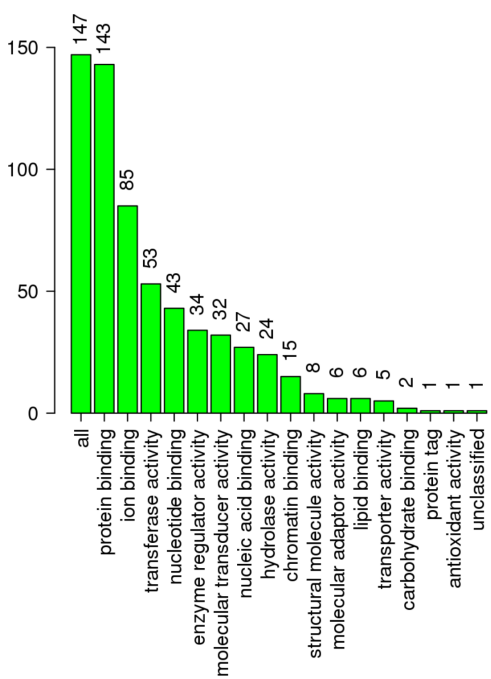

Bar chart of Molecular Function categories

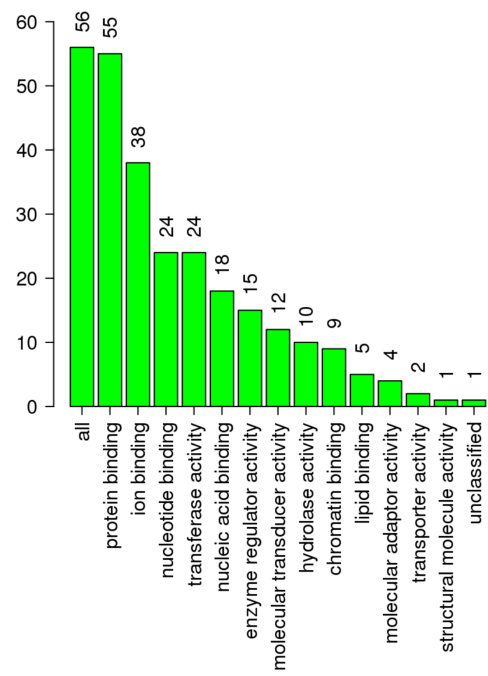

(b)

FIGURE 2 GO enrichment analysis of PTTGs related to (a) BCSCs and (b) HER2-BCSCs.

of cancer, which is also crucial to initiate metastasis, as was notable in breast cancer (Hsu and Hung 2016). Another study by Hermawan and Putri (2020) explored the target of brazilin (one of the major compounds in C. sappan L.) in the TNBC metastatic breast cancer model revealed that the inhibition of brazilin was possible through blocking in the TNF $\alpha$ pathway. Different features partly influence this distinct mechanism from TNBC with any other subtypes (including ER+ and HER2+).

This study revealed that the generation of mammospheres using polyHEMA-coated dish under conditioned medium, which is the medium used for culturing cells from splitting to achieve $80 \%$ confluency, was also interesting and successfully utilized in prior studies by using agarosecoating (Bashari et al. 2016, 2019). The medium for cell growth into the mammospheres consisted of several components, as described in Oak et al. (2012). The possible reason why the waste medium transformed $2 \mathrm{D}$ cells into $3 \mathrm{D}$ cells is that the medium lacked the nutrients. Thus, the cells were found to be in distress and differentiated to survive rather than multiply (Fadaka et al. 2017). Moreover, the MCF-7 cells contained self-renewing mammosphereforming units (MFUs) (Piggott et al. 2011), and the existence of HER2 was also responsible for regulating cell differentiation into mammospheres (Shah and Osipo 2016).

Treatment with EES exerts cytotoxicity that appeared to be more sensitive in BCSCs than in HER2-BCSCs. Previous studies using 2D model cells by Khamsita et al. (2012) and Rachmady et al. (2016) revealed that EES exhibited a cytotoxic effect on the MCF-7 and MCF-7/HER2 


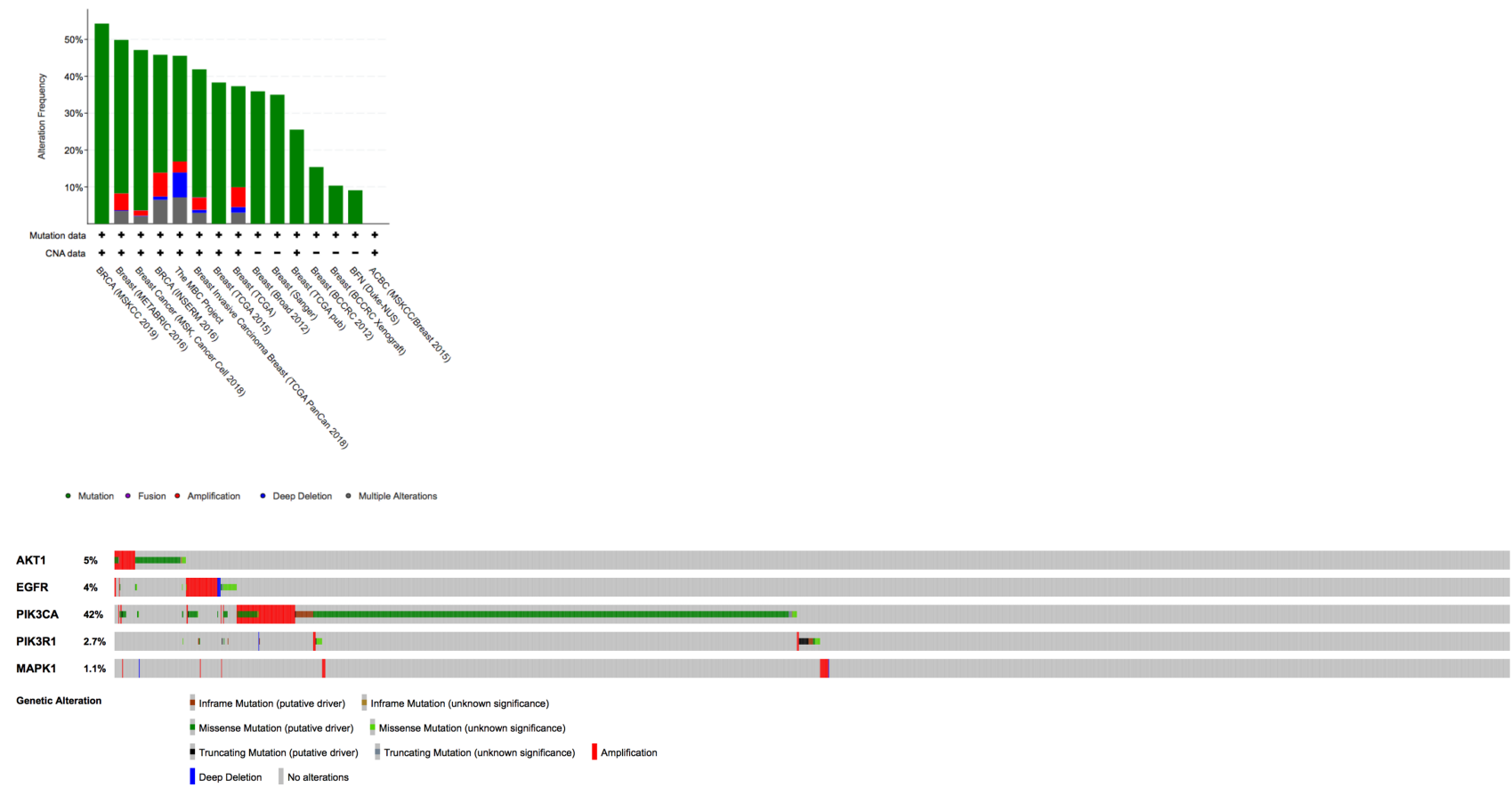

(a)

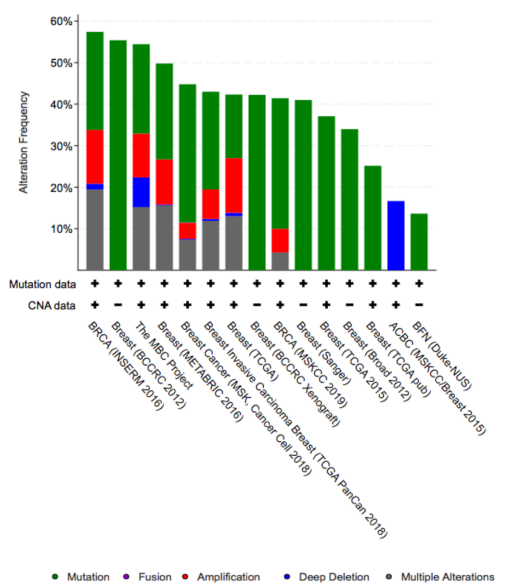

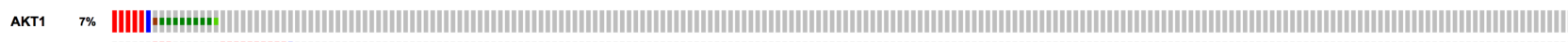

Egre $\quad$ r

Kass $\quad$ \%

myc $\quad$ 19\%

TP53 $92 \%$,

msps
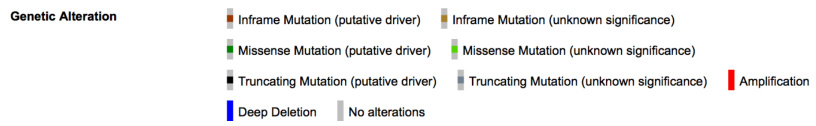

(b)

FIGURE 3 Summary alterations of hub genes among breast cancer studies and oncoprint of hub genes related to (a) BCSCS and (b) HER2BCSCs.

cells with an $\mathrm{IC}_{50}$ value of $37 \mu \mathrm{g} / \mathrm{mL}$ and $25 \mu \mathrm{g} / \mathrm{mL}$, respectively. Unlike the prior studies, the treatment of EES on the mammospheres took a longer time than the $2 \mathrm{D}$ model, which is likely due to the mammospheres' complexity, which required more incubation time for EES to inhibit mammospheres. According to the study by Konki- malla et al. (2009) and (Hsieh et al. 2013), brazilein, one of the major compounds in sappan, was proven to inactivate NFKB in the nucleus, causing the suppression of HER2. The feasible explanation of the mechanism, in this case, was the HER2 protein expression was not only associated with cell proliferation but also the CSCs progression, 

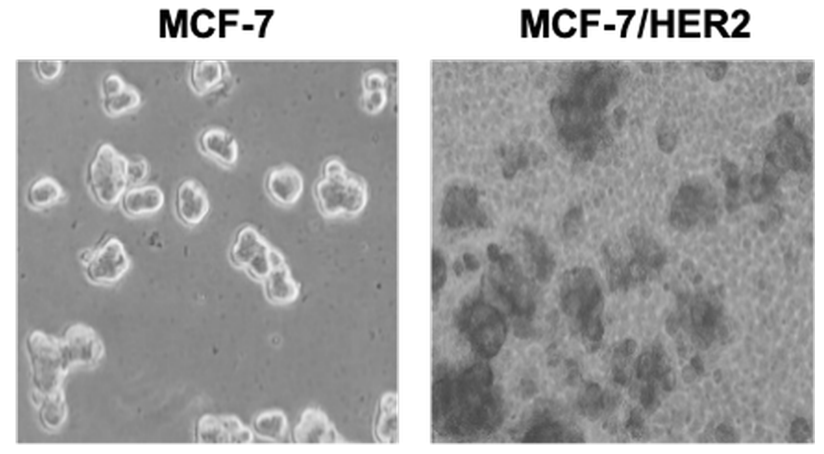

(a)

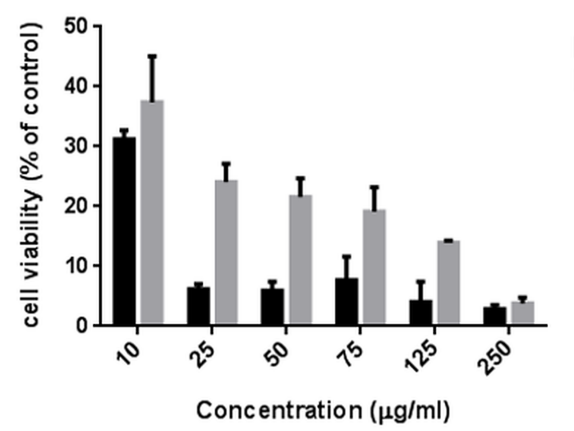

(b)
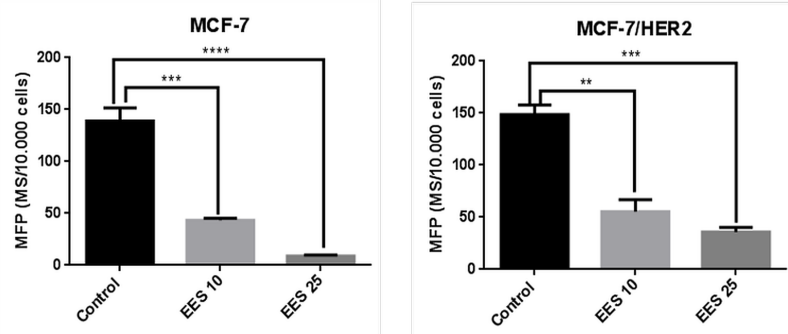

(c)

FIGURE 4 (a) Mammosphere formation from the MCF-7 and MCF7/HER2 cells under inverted microscope (magnification 400x); (b) the cytotoxicity of EES on mammospheres from the MCF-7 and MCF-7/HER2 cells; (c) EES inhibits mammosphere formation from the MCF-7 and MCF-7/HER2 cells. The results represent the average of three independent experiments (mean \pm SD). Statistical analyses were conducted by using Student's t-test. ${ }^{* *}$ or ${ }^{* * *}$ or ${ }^{* * * *}$ indicates $p<0.01$ or $p<0.001$ or 0.0001 , respectively.

which affected the cell growth more aggressively (Korkaya et al. 2008; Oak et al. 2012; Shah and Osipo 2016). Furthermore, the HER2 expression itself was regulated by NFkB (nuclear factor-kappa B). Simultaneously, HER2 could activate NFkB, majorly via IKK $\alpha$ that was primarily associated with the invasive phenotype in HER2-positive breast cancer (Merkhofer et al. 2010). Nevertheless, the NFkB activation resulted in increased mammosphere formation in cell lines derived from the HER2-dependent cancer cells (Shah and Osipo 2016).

The current study serves as a limitation as it is interesting to exert a physiological significance because, in vivo, data was not present. However, we highlighted that EES reduced the viability of BCSCs and HER2-BCSCs and predicted the target with bioinformatics studies. There- fore, a different approach needs to be explored to better understand how EES inhibited CSCs formation, particularly in the ERBB pathway. We believe that further evaluation of EES using HER2 mutant through the in vitro and in vivo assays should be interesting to elucidate the anticancer effect from $C$. sappan. These findings eventually added a new possible EES approach to act as an anticancer agent targeted on BCSCs.

\section{Conclusions}

Through this study, we summarized that the EES exhibited a cytotoxic effect and inhibited colony formation on BCSCs and HER2-BCSCs. More importantly, the PTTGs found responsible for the effects of EES in BCSCs and HER2-BCSCs were EGFR, VEGFA, TP53, STAT3, and PIK3CA. Furthermore, EES could possibly inhibit BCSCs and HER2-BCSCs through the inhibition of the ERBB signaling.

\section{Acknowledgments}

The authors acknowledged the financial support from the Ministry of Research, Technology, and Higher Education of the Republic of Indonesia for granting this study through Program Kreativitas Mahasiswa (PKM-PE) 2016. The authors thank Badan Penerbit dan Publikasi Universitas Gadjah Mada for assistance in writing.

\section{Authors' contributions}

AH, EM designed the study. DN, LM, NFS carried out the laboratory work. DN, LM, NFS, AH analyzed the data. DN and AH wrote the manuscript. All authors read and approved the final version of the manuscript.

\section{Competing interests}

The author declare that they have no competing interest.

\section{References}

Arteaga CL. 2011. ERBB receptors in cancer: signaling from the inside. Breast Cancer Res. 13(2):304. doi:10.1186/bcr2829.

Bashari MH, Fan F, Vallet S, Sattler M, Arn M, LucknerMinden C, Schulze-Bergkamen H, Zörnig I, Marme F, Schneeweiss A, Cardone MH, Opferman JT, Jäger D, Podar K. 2016. Mcl-1 confers protection of Her2-positive breast cancer cells to hypoxia: therapeutic implications. Breast Cancer Res. 18(1):26. doi:10.1186/s13058-016-0686-4.

Bashari MH, Huda F, Tartila TS, Shabrina S, Putri T, Qomarilla N, Atmaja H, Subhan B, Sudji IR, Meiyanto E. 2019. Bioactive Compounds in the Ethanol 
Extract of Marine Sponge Stylissa carteri Demonstrates Potential Anti-Cancer Activity in Breast Cancer Cells. Asian Pac J Cancer Prev. 20(4):1199-1206. doi:10.31557/APJCP.2019.20.4.1199.

Butti R, Das S, Gunasekaran VP, Yadav AS, Kumar D, Kundu GC. 2018. Receptor tyrosine kinases (RTKs) in breast cancer: signaling, therapeutic implications and challenges. Mol Cancer. 17(1):34. doi:10.1186/s12943-018-0797-x.

Cerami E, Gao J, Dogrusoz U, Gross BE, Sumer SO, Aksoy BA, Jacobsen A, Byrne CJ, Heuer ML, Larsson E, et al. 2012. The cBio cancer genomics portal: an open platform for exploring multidimensional cancer genomics data. Cancer Discovery. 2(5):401-404. doi:10.1158/2159-8290.CD-12-0095.

Cortés J, Calvo E, Vivancos A, Perez-Garcia J, Recio JA, Seoane J. 2014. New approach to cancer therapy based on a molecularly defined cancer classification. CA: Cancer J Clin. 64(1):70-74. doi:10.3322/caac.21211.

Cuong TD, Hung TM, Kim JC, Kim EH, Woo MH, Choi JS, Lee JH, Min BS. 2012. Phenolic compounds from Caesalpinia sappan heartwood and their antiinflammatory activity. J Nat Prod. 75(12):2069-2075. doi:10.1021/np3003673.

Fadaka A, Ajiboye B, Ojo O, Adewale O, Olayide I, Emuowhochere R. 2017. Biology of glucose metabolization in cancer cells. J Oncol Sci. 3(2):45-51. doi:10.1016/j.jons.2017.06.002.

Gao J, Aksoy BA, Dogrusoz U, Dresdner G, Gross B, Sumer SO, Sun Y, Jacobsen A, Sinha R, Larsson E, et al. 2013. Integrative analysis of complex cancer genomics and clinical profiles using the cBioPortal. Sci Signal 6(269):pl1. doi:10.1126/scisignal.2004088.

Garraway LA, Jänne PA. 2012. Circumventing cancer drug resistance in the era of personalized medicine. Cancer Discovery. 2(3):214-226. doi:10.1158/21598290.CD-12-0012.

Grimshaw MJ, Cooper L, Papazisis K, Coleman JA, Bohnenkamp HR, Chiapero-Stanke L, TaylorPapadimitriou J, Burchell JM. 2008. Mammosphere culture of metastatic breast cancer cells enriches for tumorigenic breast cancer cells. Breast Cancer Res. 10(3):R52. doi:10.1186/bcr2106.

Handayani S, Susidarti RA, Jenie RI, Meiyanto E. 2017. Two Active Compounds from Caesalpinia sappan L. in Combination with Cisplatin Synergistically Induce Apoptosis and Cell Cycle Arrest on WiDr Cells. Adv Pharm Bull. 7(3):375-380. doi:10.15171/apb.2017.045.

Handayani S, Susidarti RA, Udin Z, Meiyanto E, Jenie RI. 2016. Brazilein in Combination with Cisplatin Inhibit Proliferation and Migration on Highly Metastatic Cancer Cells, 4T1. Indones J Biotechnol. 21(1):38-47. doi:10.22146/ijbiotech.26106.

Hanif N, Hermawan A, Meiyanto E. 2019. Caesalpinia sappan L. Ethanolic Extract Decrease Intracellular ROS Level and Senescence of
4T1 Breast Cancer Cells. Indonesian Journal of Cancer Chemoprevention 10(1):16-23. doi:10.14499/indonesianjcanchemoprev10iss1pp1623.

Haryanti S, Pramono S, Murwanti R, Meiyanto E. 2016. The synergistic effect of doxorubicin and ethanolic extracts of Caesalpinia sappan L. wood and Ficus septica Burm. f. leaves on viability, cell cycle progression, and apoptosis induction of MCF7 cells. Indones J Biotechnol. 21(1):29-37. doi:10.22146/ijbiotech.26105.

Hermawan A, Putri H. 2020. Integrative Bioinformatics Analysis Reveals Potential Target Genes and TNF $\alpha$ Signaling Inhibition by Brazilin in Metastatic Breast Cancer Cells. Asian Pac J Cancer Prev. 21(9):27512762. doi:10.31557/APJCP.2020.21.9.2751.

Hsieh CY, Tsai PC, Chu CL, Chang FR, Chang LS, Wu YC, Lin SR. 2013. Brazilein suppresses migration and invasion of MDA-MB-231 breast cancer cells. Chem Biol Interact. 204(2):105-115. doi:10.1016/j.cbi.2013.05.005.

Hsu JL, Hung MC. 2016. The role of HER2, EGFR, and other receptor tyrosine kinases in breast cancer. Cancer Metastasis Rev. 35(4):575-588. doi:10.1007/s10555-016-9649-6.

Jenie R, Handayani S, Susidarti RA, Meiyanto E. 2020. The Effect of Brazilin from Caesalpinia sappan on Cell Cycle and Modulation and Cell Senescence in T47D cells. Indones J Pharm. 31(2):84. doi:10.14499/indonesianjpharm31iss2pp84. Number: 2 .

Jenie RI, Handayani S, Susidarti RA, Udin LZ, Meiyanto E. 2018. The Cytotoxic and Antimigratory Activity of Brazilin-Doxorubicin on MCF7/HER2 Cells. Adv Pharm Bull. 8(3):507-516. doi:10.15171/apb.2018.059.

Khamsita R, Hermawan A, Putri DDP, Meiyanto E. 2012. Ethanolic Extract of Secang (Caesalpinia sappan L.) Wood Performs as Chemosensitizing Agent Through Apoptotic Induction on Breast Cancer MCF-7 Cells. Indones J Cancer Chemoprevention. 3(3):444-449. doi:10.14499/indonesianjcanchemoprev3iss3pp444449.

Kim EC, Hwang YS, Lee HJ, Lee SK, Park MH, Jeon BH, Jeon CD, Lee SK, Yu HH, You YO. 2005. Caesalpinia sappan Induces Cell Death by Increasing the Expression of p53 and p21WAF1/CIP1 in Head and Neck Cancer Cells. Am J Chin Med. 33(03):405-414. doi:10.1142/S0192415X05003016. Publisher: World Scientific Publishing Co.

Kim SH, Kim B, Kim SH, Jeong SJ, Sohn EJ, Jung JH, Lee MH. 2012. Brazilin induces apoptosis and G2/M arrest via inactivation of histone deacetylase in multiple myeloma U266 cells. J Agric. Food Chem. 60(39):9882-9889. doi:10.1021/jf302527p.

Konkimalla VB, McCubrey JA, Efferth T. 2009. The role of downstream signaling pathways of the epidermal growth factor receptor for Artesunate's activity in 
cancer cells. Curr Cancer Drug Targets. 9(1):72-80.

Korkaya H, Paulson A, Iovino F, Wicha MS. 2008. HER2 regulates the mammary stem/progenitor cell population driving tumorigenesis and invasion. Oncogene. 27(47):6120-6130. doi:10.1038/onc.2008.207.

Koury J, Zhong L, Hao J. 2017. Targeting Signaling Pathways in Cancer Stem Cells for Cancer Treatment. Stem Cells Int. 2017. doi:https://doi.org/10.1155/2017/2925869.

Kroschinsky F, Stölzel F, von Bonin S, Beutel G, Kochanek M, Kiehl M, Schellongowski P, Intensive Care in Hematological and Oncological Patients (iCHOP) Collaborative Group. 2017. New drugs, new toxicities: severe side effects of modern targeted and immunotherapy of cancer and their management. Crit Care. 21(1):89. doi:10.1186/s13054-017-1678-1.

Kuhn M, Szklarczyk D, Pletscher-Frankild S, Blicher TH, Von Mering C, Jensen LJ, Bork P. 2014. STITCH 4: Integration of protein-chemical interactions with user data. Nucleic Acids Res. 42(D1). doi:10.1093/nar/gkt1207.

Lefebvre C, Bachelot T, Filleron T, Pedrero M, Campone M, Soria JC, Massard C, Lévy C, Arnedos M, Lacroix-Triki M, et al. 2016. Mutational Profile of Metastatic Breast Cancers: A Retrospective Analysis. PLoS Med. 13(12):e1002201. doi:10.1371/journal.pmed.1002201. Publisher: Public Library of Science.

Masuda H, Zhang D, Bartholomeusz C, Doihara H, Hortobagyi GN, Ueno NT. 2012. Role of Epidermal Growth Factor Receptor in Breast Cancer. Breast Cancer Res Treat. 136(2). doi:10.1007/s10549-012-2289-9.

Meiyanto E, Lestari B, Sugiyanto RN, Jenie RI, Utomo RY, Sasmito E, Murwanti R. 2019. Caesalpinia sappan L. heartwood ethanolic extract exerts genotoxic inhibitory and cytotoxic effects. Orient Pharm Exp Med. 19(1):27-36. doi:10.1007/s13596-018-0351-9.

Merkhofer EC, Cogswell P, Baldwin AS. 2010. Her2 activates NF-kB and induces invasion through the canonical pathway involving IKK $\alpha$. Oncogene. 29(8):12381248. doi:10.1038/onc.2009.410.

Naik Bukke A, Nazneen Hadi F, Babu KS, shankar PC. 2018. In vitro studies data on anticancer activity of Caesalpinia sappan L. heartwood and leaf extracts on MCF7 and A549 cell lines. Data Brief. 19:868-877. doi:10.1016/j.dib.2018.05.050.

Nirmal NP, Rajput MS, Prasad RG, Ahmad M. 2015. Brazilin from Caesalpinia sappan heartwood and its pharmacological activities: A review. Asian Pac J Trop Med. 8(6):421-430. doi:10.1016/j.apjtm.2015.05.014.

Nurzijah I, Putri DDP, Rivanti E, Meiyanto E. 2012. Secang (Caesalpinia sappan L.) Heartwood Ethanolic Extract Shows Activity as Doxorubicin Co-chemotherapeutic Agent by Apoptotis Induction on T47D Breast Cancer Cells. Indones J Cancer Chemoprevention. 3(2):376-383. doi:10.14499/indonesianjcanchemoprev3iss2pp376-
383. Number: 2.

Oak PS, Kopp F, Thakur C, Ellwart JW, Rapp UR, Ullrich A, Wagner E, Knyazev P, Roidl A. 2012. Combinatorial treatment of mammospheres with trastuzumab and salinomycin efficiently targets HER2-positive cancer cells and cancer stem cells. Int J Cancer. 131(12):2808-2819. doi:10.1002/ijc.27595.

Piggott L, Omidvar N, Pérez SM, Eberl M, Clarkson RW. 2011. Suppression of apoptosis inhibitor c-FLIP selectively eliminates breast cancer stem cell activity in response to the anti-cancer agent, TRAIL. Breast Cancer Res. 13(5):R88. doi:10.1186/bcr2945.

Rachmady R, Muntafiah L, Rosyadi F, Sholihah I, Handayani S, Jenie RI. 2016. Antiproliferative Effect of Secang Heartwood Ethanolic Extract (Caesalpinia sappan L.) on HER2-Positive Breast Cancer Cells. Indones J Cancer Chemoprevention. 7(1):1-5. doi:10.14499/indonesianjcanchemoprev7iss1pp1-5.

Rivanti E, Shabrina BA, Nurzijah I, Ayu C, Hermawan A. 2016. Heartwood of Secang (Caesalpinia sappan L.) Ethanolic Extract Show Selective Cytotoxic Activities on T47D and Widr Cells But Not on Hela Cells. Indones J Cancer Chemoprevention. 7(2):60-67. doi:10.14499/indonesianjcanchemoprev7iss2pp6067. Number: 2.

Shah D, Osipo C. 2016. Cancer stem cells and HER2 positive breast cancer: The story so far. Genes Dis. 3(2):114-123. doi:10.1016/j.gendis.2016.02.002.

Shannon P, Markiel A, Ozier O, Baliga NS, Wang JT, Ramage D, Amin N, Schwikowski B, Ideker T. 2003. Cytoscape: a software environment for integrated models of biomolecular interaction networks. Genome Res 13(11):2498-2504. doi:10.1101/gr.1239303.

Szklarczyk D, Franceschini A, Wyder S, Forslund K, Heller D, Huerta-Cepas J, Simonovic M, Roth A, Santos A, Tsafou KP, Kuhn M, Bork P, Jensen LJ, von Mering C. 2015. STRING v10: protein-protein interaction networks, integrated over the tree of life. Nucleic Acids Res 43(Database issue):D447-452. doi:10.1093/nar/gku1003.

Wang J, Vasaikar S, Shi Z, Greer M, Zhang B. 2017. WebGestalt 2017: a more comprehensive, powerful, flexible and interactive gene set enrichment analysis toolkit. Nucleic Acids Res. 45(W1):W130-W137. doi:10.1093/nar/gkx356.

Wang R, Lv Q, Meng W, Tan Q, Zhang S, Mo X, Yang X. 2014. Comparison of mammosphere formation from breast cancer cell lines and primary breast tumors. J Thorac Dis. 6(6):829-837. doi:10.3978/j.issn.20721439.2014.03.38. 